\title{
Modulation of the activity of certain genes involved in tumor cell metabolism in the presence of the cytotoxic peptides defensin and cathelicidin LL37
}

\author{
TEODOR ȘTEFANACHE ${ }^{1}$, NORINA FORNA ${ }^{2}$, MAGDA BĂDESCU ${ }^{1}$, DANIELA JITARU ${ }^{3}$, \\ MIHAIELA LOREDANA DRAGOS ${ }^{3}$, CIPRIAN REZUS $^{4}$, BOGDAN MIHAIL DIACONESCU ${ }^{1}$, \\ OANA BĂDULESCU ${ }^{1}$, ELENA REZUȘ ${ }^{5}$, MANUELA CIOCOIU $^{1}$ and CODRUTA BĂDESCU ${ }^{4}$
${ }^{1}$ Department of Pathophysiology, ${ }^{2}$ Department of Implantology, Dental Medicine, ${ }^{3}$ Regional Institute of Oncology Iasi,
${ }^{4}$ Department of Internal Medicine and ${ }^{5}$ Rehabilitation Hospital of Iasi, Rheumatology Clinic, University of Medicine and Pharmacy 'Grigore T. Popa', 700115 Iaşi, Romania

Received July 19, 2019; Accepted August 30, 2019

DOI: $10.3892 / \mathrm{etm} .2019 .8117$

\begin{abstract}
It is common knowledge that some natural antimicrobial peptides also have a tumoricidal effect. We have shown that the peptides defensin and cathelicidin LL37 have cytostatic effects on human tumor cell lines HT29 (colorectal carcinoma) and A549 (alveolar carcinoma). In order to determine the modulating mechanism of these peptides we assessed the gene expression of the AKT, HIF-1 $\alpha, X B P, N R F 2, P E R K$, CHOP, BCL2, IRE1 $\alpha$ and PI3K molecular targets involved in the survival, growth, proliferation and apoptosis pathways of tumor cells in the presence or absence of the studied peptides. Thus, this research enabled us to determine molecular markers and methods of assessment and monitoring of tumor cell cytotoxicity by high-performance molecular biology techniques. Defensin and cathelicidin LL37 activated tumor cell apoptosis, especially for the HT29, but also for A549 line, by increasing gene expression of CHOP and by lowering BCL2 gene expression. Oxidative stress determined the increase in gene expression of XBP, which directly influenced CHOP. The decrease in NRF2 gene expression highlighted the inhibition of cell proliferation, while the decrease in HIF1 $\alpha$ gene expression evidenced the decrease in cell survival.
\end{abstract}

Correspondence to: Dr Ciprian Rezuş, Department of Internal Medicine, University of Medicine and Pharmacy 'Grigore T. Popa', 16 Universitatii Street, 700115 Iaşi, Romania

E-mail: ciprianrezus@yahoo.com

Dr Oana Bădulescu, Department of Pathophysiology, University of Medicine and Pharmacy 'Grigore T. Popa', 16 Universitatii Street, 700115 Iaşi, Romania

E-mail: violabadulescu@yahoo.com

Key words: gene expression, defensin, cathelicidin

\section{Introduction}

Despite the recent advances in cancer therapy, this malignancy remains a major source of morbidity and mortality worldwide. Although some cases of cancer can often be treated successfully by surgery and/or radiotherapy, chemotherapy remains the preferred therapy. It is a well-known fact that most of the existing cytostatic drugs allow for control of tumor growth only at concentrations that also affect healthy cells, which leads to undesirable side effects. Thus, it is imperative to find new products with new action mechanisms, and one of the current research directions is the use of cytotoxic antimicrobial peptides. These could be the new tumoricidal molecules to be used in adjuvant cancer therapy, with the potential to reduce cytostatic drug doses and their toxic side effects.

Numerous studies have shown tumoricide properties of some natural peptides known to be antimicrobial (1-3). Therefore, composition in aminoacids, amfifaticity, cationic charge and size allow cytotoxic peptides to attach and insert in the phospholipidic cell membrane layers in order to form transmembrane pores that will change the membrane permeability and will determine cell development that will lead to apoptosis $(2,3)$. Considering all these aspects, our experimental research is aimed at checking whether the cytotoxic peptides such as defensin and cathelicidin LL37 have tumoricidal potential and whether the extent of the effect depends on the nature and concentration of the peptide used in the cells' living environment, but also on the type of cell line experimentally used in vitro (4-6).

It is our goal to analyze the biological effect of these peptides (defensin and cathelicidin LL37) on the tumor cell lines HT-29 (colorectal carcinoma) and A-549 (human alveolar carcinoma). In order to determine the modulating mechanism of the chosen cytotoxic peptides the viability and gene expression of the molecular targets (AKT, HIF-1 $\alpha X B P, N R F 2$, PERK, CHOP, BCL2, IRE1 $\alpha, P I 3 K$ ) were assessed, in the sense of activating or inhibiting certain genes involved in the survival, growth, proliferation and apoptosis pathways of tumor cells in the presence or absence of the studied peptides (5-7). 
Table I. Hybridization temperature of the primers used in our study.

No crt.

XBP

CHOP

Nrf2

AKT

$\mathrm{Bcl} 2$

HIF $1 \alpha$

PERK

GAPDH

ABL

IRE $1 \alpha$

PI3K
Primers optimized for the SYBR-Green method

Hybridization

temperature

Fw CCTGGTTGCTGAAGAGGAGG

$88^{\circ} \mathrm{C}$

Rev CCATGGGGAGATGTTCTGGAG

Fw TTCTCTGGCTTGGCTGACTG

$66^{\circ} \mathrm{C}$

Rev CTGCGTATGTGGGATTGAGG

Fw AGTGGATCTGCCAACTACTC

$66^{\circ} \mathrm{C}$

Rev CATCTACAAACGGGAATGTCTG

Fw TCTATGGCGCTGAGATTGTG

$66^{\circ} \mathrm{C}$

Rev CTTAATGTGCCCGTCCTTGT

Fw CTGCACCTGACGCCCTTCACC

$72^{\circ} \mathrm{C}$

Rev CACATGACCCCACCGAACTCAAAGA

Fw CACTACCACTGCCACCACTG

$80^{\circ} \mathrm{C}$

Rev CCTTTTCCTGCTCTGTTTGG

Fw CAGTGGCAATGAGAAGTGGA

$81^{\circ} \mathrm{C}$

Rev CAGTCAGCAACCGAAACCTT

$88^{\circ} \mathrm{C}$

Fw GGGGCTCTCCAGAACATCAT

Rev AAGTGGTCGTTGAGGGCAAT

$55^{\circ} \mathrm{C}$

Rev TTCAGCGGCCAGTAGCATCTGACTT

Fw GCCTCTCCCTCAATGGTACA

$88^{\circ} \mathrm{C}$

Rev TTGGTAGACGCAGACAGTGG

Fw CTGGAAAGAAGCTGGTTTGG

$85^{\circ} \mathrm{C}$

\section{Materials and methods}

Peptides, cell lines and cell cultures. Beta Defensin 1 human $\geq 98 \%$ (HPLC), $10 \%$ acetonitrile, $0.1 \%$ TFA in $\mathrm{H}_{2} \mathrm{O}$, cationic peptides from Sigma product no. SRP3011, lot no. 090202, molecular mass $7.8 \mathrm{kDa}$ and cathelicidin LL37 human $\geq 95 \%$ (HPLC), $10 \%$ acetonitrile, $0.1 \%$ TFA in $\mathrm{H}_{2} \mathrm{O}$, cationic peptides from GenScript product no. RP-20332, lot no. PE1081804, molecular mass 4495.1 g.mol ${ }^{-1}$. Defensin and cathelicidin LL37 are positively charged, amphiphatic molecules and preferentially bind to anionic phospholipids from cell membranes with the formation of dynamic peptide-lipid supramolecular pore and cell permeabilization.

The peptides under survey (Defensin and Cathelicidin LL37) were freeze-dried in a RPMI-1640 (Sigma-Aldrich) medium ( $\mathrm{pH} 7.35)$, in a sterile environment. Consecutive peptide dilutions with RPMI-1640 (Sigma-Aldrich) were used for the two peptides, whereas the working concentrations were $20 \mu \mathrm{M}, 15 \mu \mathrm{M}$, and from 10 to $1 \mu \mathrm{M}$, ten concentrations for 1 to $1 \mu \mathrm{M}$ in $100 \mu \mathrm{l} /$ well with an optimal and constant number of cells by $10^{5}$ tumor cells/well.

We used two adherent tumor cell lines: HT-29 is a colorectal carcinoma cell line (ATCC ${ }^{\circledR}$ HTB-38 ${ }^{\mathrm{TM}}$ ) and A549 is a human alveolar carcinoma adherent cell line $\left(\mathrm{ATCC}^{\circledR} \mathrm{CCL}^{\mathrm{C}} 185^{\mathrm{TM}}\right)$.

All the tumor cell lines were cultivated in RPMI-1640 medium (Sigma-Aldrich) with 10\% FBS (fetal bovine serum;
Gibco) (1). Triplicate cell lines (with viability >97\%) were prepared for each peptide concentration. The negative control was represented by target cells incubated without peptide. In order to prevent the edge effect and preserve humidity in the plate, only culture medium was pipetted in the edge columns and lines. Their viability was determined after $48 \mathrm{~h}$ of incubation at $37^{\circ} \mathrm{C}, 5 \% \mathrm{CO}_{2}$, using the vital dye MTT [3-(4,5-dimethylthiazol-2-yl)-2,5-diphenyltetrazolium bromide] by MTT Cell Proliferation Assay kit from Cayman, product no. 10009365, lot no. 0518531 . Absorbance was measured at $595 \mathrm{~nm}$ by reference at wavelength of $620 \mathrm{~nm}$ with the FilterMax F5 Mode Microplate Reader spectrophotometer.

The second method for viability was flow cytometry using Annexin V and propidium iodide (PI) from EXBIO by ApoFlowEx ${ }^{\circledR}$ FITC kit product no. ED7044, lot no. 526846. FACSCanto II cytometer was used for data acquisition and processing using BD FACSDiva 6.12 program (both from Becton Dickinson Biosciences) (8).

Molecular biology techniques were used to detect metabolic changes in tumor cells, by assessing gene expression for particular molecular targets.

RNA extraction from tumor cell cultures was performed by automated methods with the RiboZol ${ }^{\mathrm{TM}}$ RNA Extraction Reagent from VWR AMRESCO LLC, lot no. 1587C464. The RNA solution was stored at $-20^{\circ} \mathrm{C}$ until reverse transcription in cDNA was performed. This process was accomplished by 

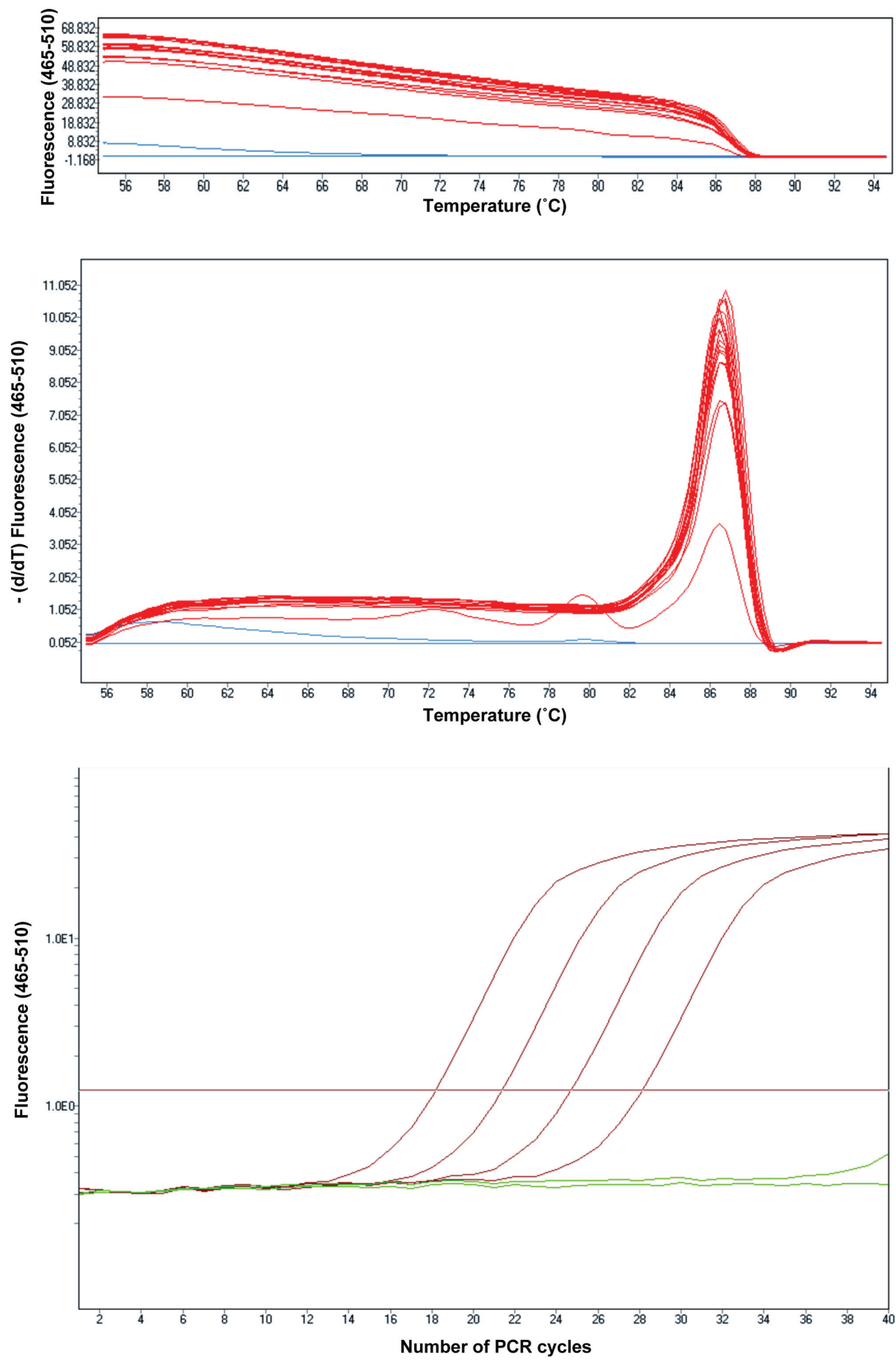

Figure 1. Melting curve for gene of reference $(A B L)$ was $55^{\circ} \mathrm{C}$, without dimers of primer and standard curves for $A B L$ gene.

using the SuperScript IV RT Enzymes kit from Promega, lot no. 0000361199 with Agilent SureCycler 8800 equipment. The complementary DNA thus obtained may be used immediately or stored for a short time at $-20^{\circ} \mathrm{C}$ or for a longer term at $-80^{\circ} \mathrm{C}$. The purity of the DNA introduced as matrix is an important parameter for the success of a PCR reaction.

An in-house method of qRT-PCR with SYBR-Green (Promega product no. A6001, lot no. 0000322091) was used. This method requires a melting curve at the end of the amplification stage, which translates into a slowly and incrementally growing temperature gradient $\left(1^{\circ} \mathrm{C}\right.$ approximately every
2-3 sec) starting from the hybridization temperature of the primers (Table I) up to the temperature of denaturation of the entire reaction mixture.

The fluorescence obtained by melting the reaction products were read in each denaturation stage. Each product resulting in the amplification reaction thus produces a melting peak. Depending on the melting temperature of the product(s) and the number of peaks obtained, the specificity of the reaction may be interpreted (Fig. 1).

The desired amplicons of different concentrations were obtained through RT-PCR amplification, which were 
FACSDiva version 6.1.3

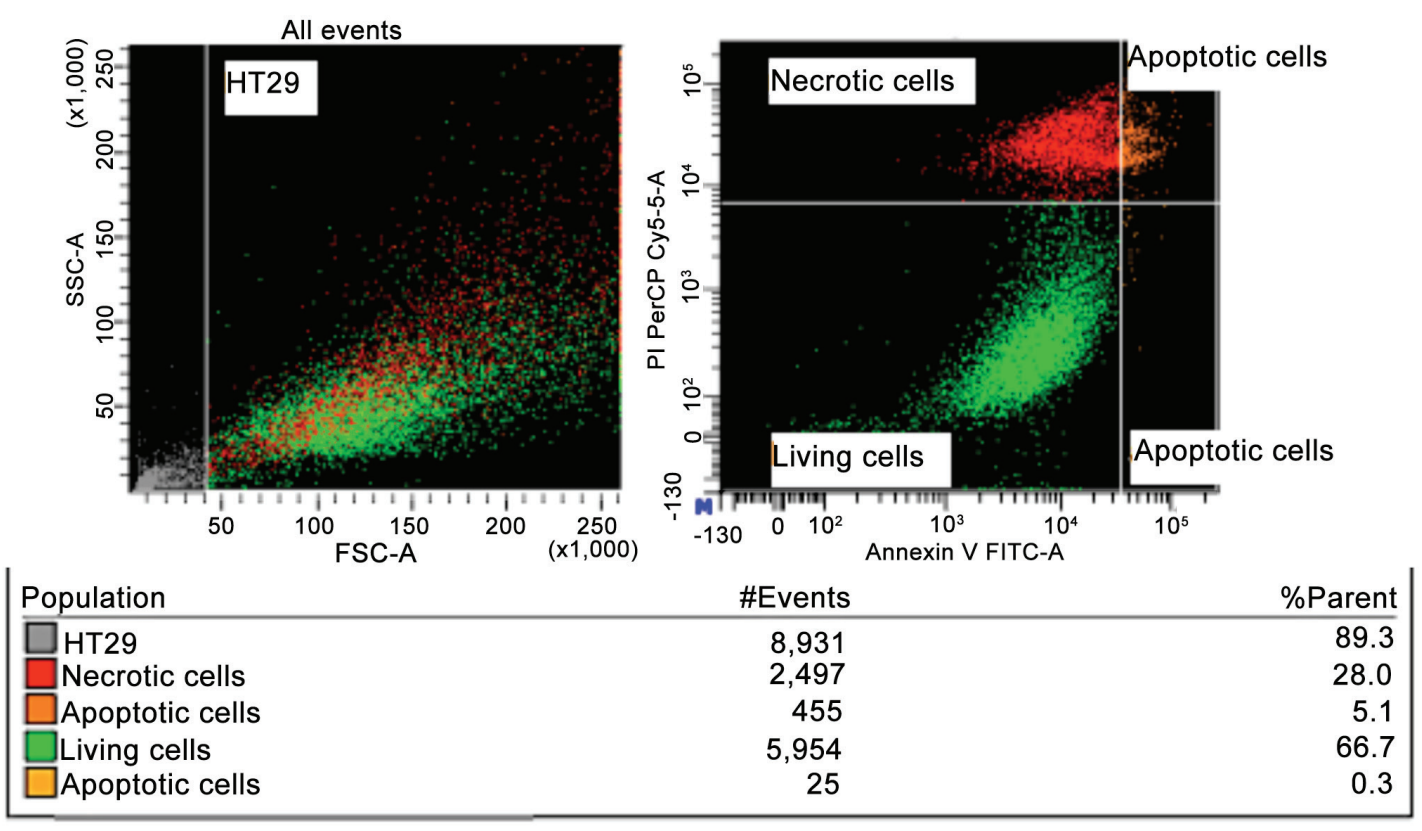

Figure 2. Flow cytometry results for the HT29 cell line with defensin $4 \mu \mathrm{M}$ after $48 \mathrm{~h}$ incubation.

compared to the concentration of GAPDH extracted from each cell line used in the experiment. Results were reported as percentages of increase or decrease of the gene expression compared to the control, as compared to the reference gene $(G A P D H): \%$ gene $=$ number of amplicon genes $/ \mu \mathrm{l} /$ reference gene $(G A P D H) \times 100$.

Statistical method. For the study we used GraphPad Prism 5, t-test and Excel method of calculation for gene expression percent. Data analysis results are presented as the mean \pm S.E.M. Means of 2 continuous normally distributed variables were compared by independent samples Student's t-test. $\mathrm{P}<0.05$ was considered to indicate a statistically significant difference.

\section{Results}

Determination of the cytotoxicity of defensin and cathelicidin LL37. For the HT-29 tumor line, when the defensin concentration was $4 \mu \mathrm{M}$, the MTT colorimetric technique revealed intense cytotoxicity $(\mathrm{P}<0.001)$, which was also demonstrated by flow cytometry, when a $33.4 \%$ apoptosis was obtained after $48 \mathrm{~h}$ incubation (Fig. 1). Cytotoxicity was also significant when incubation occurred at the high $15 \mu \mathrm{M}$ and $20 \mu \mathrm{M}$ concentrations. This was revealed by both the MTT method $(\mathrm{P}<0.001)$ and by the flow cytometry method, with $57 \%$ apoptosis at a defensin concentration of $15 \mu \mathrm{M}$, and only $10 \%$ for the control (cells that were not incubated with the peptide).

For the A549 tumor line, when the defensin concentration was $4 \mu \mathrm{M}$, the MTT colorimetric technique revealed intensive statistically significant cytotoxicity $(\mathrm{P}<0.001)$, which was also demonstrated by flow cytometry, when a significant $52 \%$ apoptosis was obtained after $48 \mathrm{~h}$ incubation (Fig. 2). Cytotoxicity was also intensive when incubation occurred at the high $15 \mu \mathrm{M}$ and $20 \mu \mathrm{M}$ concentrations. This was revealed by both the MTT method $(\mathrm{P}<0.001)$ and by the flow cytometry method, with $32 \%$ apoptosis and $10 \%$ cell mortality rate.

Addition of cathelicidin LL37, after $48 \mathrm{~h}$ incubation, by flow cytometry revealed significant apoptosis only for the high peptide concentrations $(15 \mu \mathrm{M})$. Of these cells $83.67 \%$ were in late apoptosis compared to the incubation of these cells at $4 \mu \mathrm{M}$ concentrations, for which the behavior of the cells was similar to that of the negative control.

Gene expression changes in the selected molecular targets, under defensin action. The experimental findings achieved for the HT-29 and A549 tumor cell lines, used molecular biology techniques to determine the gene expression of some molecular targets involved in the metabolic reprogramming of the tumor cell both in the presence and in the absence of peptides with tumoricidal potential (defensin and cathelicidin LL37). These molecular targets refer to genes involved in the pro-apoptotic pathway (CHOP, XBPI, IRE1 $\alpha, P E R K)$ and anti-apoptotic pathway (BCL2), as well as to genes that stimulate cell proliferation $(N R F 2)$ and survival $(A K T, H I F \alpha$, PIK3).

The analysis of the findings revealed a significant increase (80\%) in the CHOP gene expression in the HT29 line incubated with $4 \mu \mathrm{M}$ defensin for $48 \mathrm{~h}$ (HT4), compared to the control (HT0), and $2 \%$ increase for the A549 line incubated with $4 \mu \mathrm{M}$ defensin for $48 \mathrm{~h}$ (A4), compared to control (A0). The increase in CHOP gene expression was $16 \%$ in non-peptide cells $24 \mathrm{~h}$ after incubation, and there was no change in the cells incubated with $15 \mu \mathrm{M}$ peptide for $24 \mathrm{~h}$.

The analysis of these findings revealed a significant increase $(302.67 \%)$ in the $A K T$ gene expression in the HT29 line incubated with $15 \mu \mathrm{M}$ defensin for $48 \mathrm{~h}$ (HT15), 

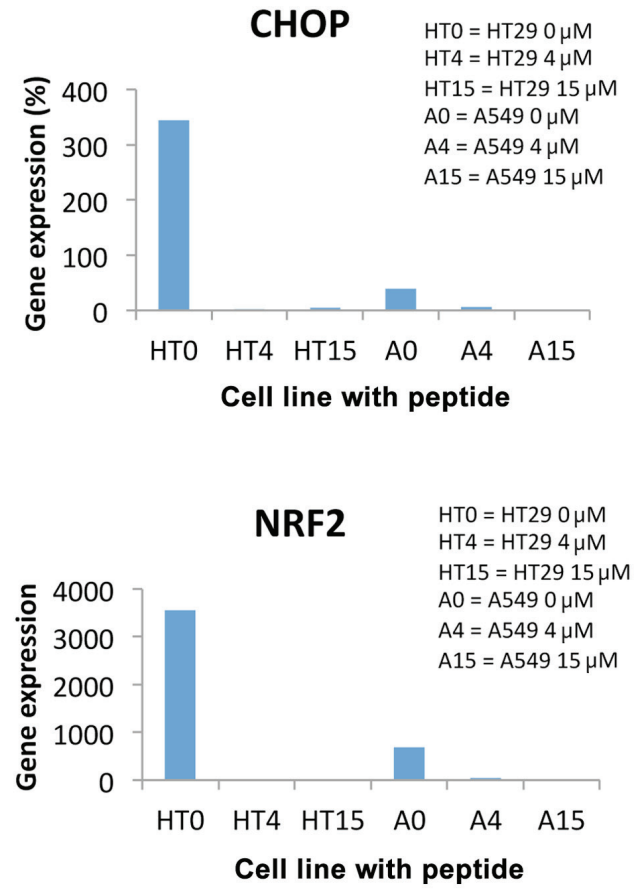
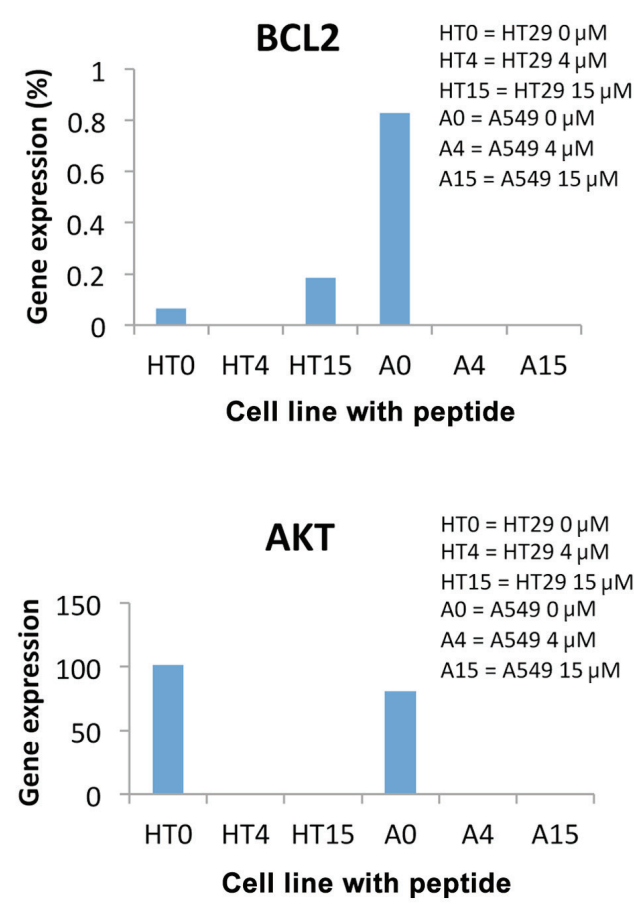

Figure 3. Gene expression quantification for the $C H O P, B C L 2, N R F 2, A K T$ genes compared to the $G A P D H$ reference gene: $\%$ gene expression = number of amplicons gene/ $\mu 1 /$ reference gene $(G A P D H) \times 100$.

compared to the control (HT0), for which the increase reached 92.04\% compared to the $A B L$ reference gene. The increase for the A549 line incubated with defensin was $76.48 \%$ (A15) compared to A0.

For the NRF gene expression in the HT29 line, a 2-fold decrease in gene expression in the $15 \mu \mathrm{M}$ defensin-treated tumor over the untreated line was observed. Also, approximately fourfold decrease was observed in the A549 line treated with $4 \mu \mathrm{M}$ defensin incubated for $48 \mathrm{~h}$ (A4), compared to the control $(\mathrm{A} 0)$.

The $X B P$ gene expression presented a highly significant 45 -fold increase in the gene expression in the $4 \mu \mathrm{M}$ defensin-treated HT29 line and a 15-fold increase for the $15 \mu \mathrm{M}$ defensin concentration compared to the untreated line. Furthermore, the increase was $248.32 \%$ in the A549 line incubated with $15 \mu \mathrm{M}$ for $48 \mathrm{~h}$ (A15), compared to the control (A0, for which the increase was $94.2 \%$ compared to the ABL reference gene), showing, a 3 -fold increase in the gene expression in $X B P$.

The findings for the $P E R K$ gene expression revealed a 2-fold decrease in the gene expression only in the A549 line incubated with $4 \mu \mathrm{M}$ concentrated peptide, and showed no expression whatsoever at higher peptide concentrations. Gene expression is absent for the HT29 defensin-incubated line compared to the control that expressed this gene.

Gene expression changes in the selected molecular targets for HT29 and A549, under cathelicidin LL37 action. CHOP gene expression for the HT29 cell line decreased 1.5-fold over the control and 300-fold as a percentage relative to the reference gene ABL at $4 \mu \mathrm{M}$ cathelicidin LL37 concentration. It also decreased significantly against the control at $15 \mu \mathrm{M}$ concentration. This indicates that under toxic conditions, the CHOP gene that is involved in the pro-apoptotic pathway of the cell decreases its expression and thus has an anti-apoptotic effect. Compared to line A549, for which CHOP gene expression is 3-fold higher at $4 \mu \mathrm{M}$ and only 2 -fold higher at $15 \mu \mathrm{M}$. This indicates that, at lower concentrations of cytotoxic peptide, the neoplastic cell evolves towards apoptosis faster than at high concentrations (Fig. 3).

The BCL2 gene expression is involved in the anti-apoptotic pathway of the cell, i.e., in supporting its survival and therefore, in toxic conditions, its gene expression should decrease (Fig. 3).

When cathelicidin LL37 occurred in its living environment, the HT29 line showed a 4.5 -fold increase at $4 \mu \mathrm{M}$ concentrations and a 16 -fold increase at $15 \mu \mathrm{M}$ concentration of the gene expression compared to the control, which means improved cell defense. As for the A549 line, a significant 13 -fold decrease was noted in gene expression at $4 \mu \mathrm{M}$ and a 19 -fold decrease at $15 \mu \mathrm{M}$, showing poorer cell defense. This proves that cathelicidin LL37 has a tumoricidal effect on the A549 cell line.

The manner in which cathelicidin LL37 influenced cell proliferation was determined by assessing the expression of the NRF2 gene, which presented a 274 -fold decrease at $4 \mu \mathrm{M}$ concentration and total suppression at $15 \mu \mathrm{M}$ concentration, in the HT29 line. Therefore, although it triggers an improvement in cell defense by modifying pro- and anti-apoptotic gene expression, this peptide significantly reduces or blocks tumor cell proliferation. For the A549 line, a similar evolution was noted, as $N R F 2$ gene expression decreased 58 -fold at $4 \mu \mathrm{M}$ concentration and 46-fold at $15 \mu \mathrm{M}$ concentration (Fig. 3 ).

$A K T$ gene expression decreased dramatically in both cell lines, namely over 80 times regardless of the peptide concentration (Fig. 4). This meant that cell survival and proliferation was intensely inhibited regardless of the peptide concentration, for both cell lines. 

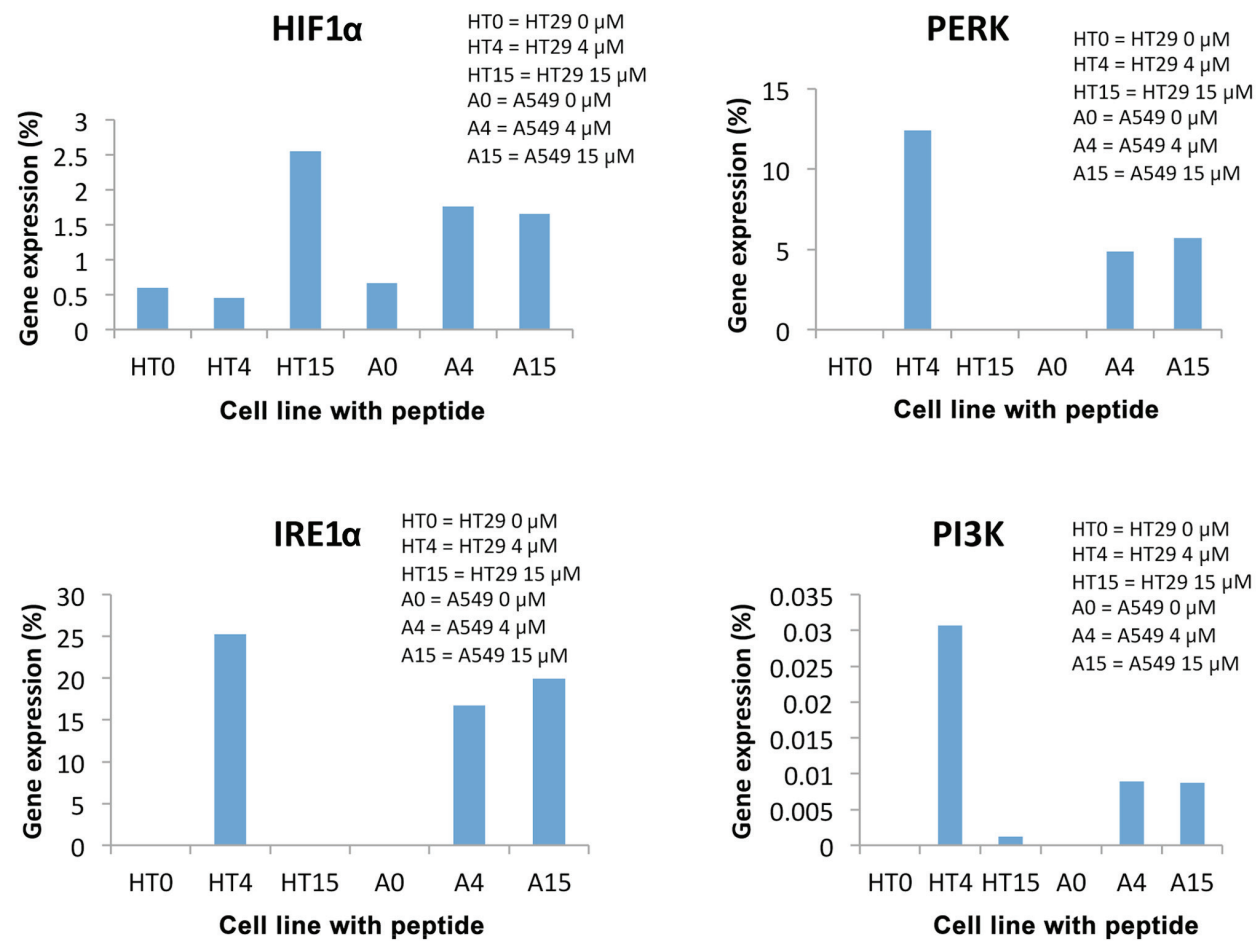

Figure 4. Gene expression quantification for the HIF1 $\alpha, P E R K, P I 3 K, I R E$ genes compared to the GAPDH reference gene: \% gene expression $=$ number of amplicons gene/ $/ \mathrm{l} /$ reference gene $(G A P D H) \times 100$.

Our findings also revealed the presence of RE stress in the tumor cells. Expression of IREI $\alpha$ and PI3K genes was not high for control tumor cells, only for peptide-incubated cathelicidin LL37, which indicates the presence of stress in the peptide-incubated tumor cells (Fig. 4).

\section{Discussion}

Our study was aimed at determining the tumoricidal potential of defensin and cathelicidin LL37 by measuring cell viability by flow cytometry for peptide concentrations which triggered significant apoptosis as evaluated by the MTT method. Defensin concentrations to test viability by flow cytometry at $4 \mu \mathrm{M}(\mathrm{P}<0.01)$ and $15-20 \mu \mathrm{M}(\mathrm{P}<0.001)$ were used. The findings achieved for the two cell lines HT-29 and A549 are different under defensin action; at $15 \mu \mathrm{M}$ concentration, cell apoptosis showed a 2 -fold increase in the colorectal carcinoma line compared to the alveolar carcinoma line. For cathelicidin LL37, the viability of both tumor cell lines was significantly influenced, and toxicity was significant $(\mathrm{P}<0.01)$.

Defensin, a cationic peptide, increased $C H O P$ gene expression in both tumor cell lines, which indicates the increase of apoptotic protein synthesis as well as oxidative stress, also emphasized by augmentation of $X B P$ gene expression. The findings achieved for the two cell lines are significantly different under the action of defensin at $15 \mu \mathrm{M}$ concentrations, cell apoptosis was 2 -fold higher in the colorectal carcinoma line as compared to the alveolar carcinoma line. This explains the increase of $X B P$ gene expression in the HT29 cells, whose fight for survival was fiercer. ER stress may be a potential target for the development of new cancer therapy able to reduce adaptation to hypoxia, inflammation and angiogenesis of tumor cells, so that resistance to cytostatic therapy may be prevented (9-14).

On the other hand, CHOP has been shown to induce tumor cell death by stimulating the synthesis of pro-apoptotic proteins and by stimulating oxidative processes in stress-exposed cancer cells (15). Under ER stress, cancer cell increases COX2 expression via the NF- $\kappa \mathrm{B}$ pathway, which plays an important anti-apoptotic role. Also, NF- $\kappa B$ pathway activation plays an important pro-inflammatory role through CHOP, and stimulates IL- 8 synthesis as is the case in human epithelial cells (16-19).

Metabolic and inflammatory changes are important in the carcinogenesis process as they increase protein assembly and ER activity, leading to ER stress. The stress response of ER is cytoprotective and is involved in cancer cell growth and adaptation to the aggressiveness of its environment $(20,21)$. ER-located pancreatic ER kinase (PERK) is involved in carcinogenesis. PERK gene expression decreased significantly in the A549 line. The decrease or inhibition of the protein synthesis of some unfolded protein response (UPR) components such as PERK may be potential targets in cancer therapy.

Gene expression increased for members of the $B C L 2$ family that have an anti-apoptotic role has been associated with resistance to chemotherapy in various cancers (22). In our study, at low defensin concentrations $(4 \mu \mathrm{M}) B C L 2$ decreased in both tumor cell lines, thus proving a cytostatic effect by stimulating apoptosis. In the HT29 line, defensin blocks $B C L 2$ gene expression and determines a decreased anti-apoptotic protein synthese at both $15 \mu \mathrm{M}$ and $4 \mu \mathrm{M}$ concentrations.

$N R F 2$ gene expression (molecular marker for cell proliferation) is significantly inhibited in both the HT29 
and A549 lines, the effect being a drastic limitation of cell multiplication (cytostatic effect). The A549 cells were noted (23) to turn glutamine in the culture medium into glutathione under NRF2 action, thereby accelerating the proliferation of A549 cells. NRF2 may be a molecular target for cancer therapy by molecules that would inhibit NRF2 activity in tumor cells, such as defensin $(24,25)$.

$H I F 1 \alpha$ gene expression strongly decreased in both tumor lines. HIFl $\alpha$ plays an important role in tumor growth as it mediates tumor angiogenesis, proliferation and invasion, by regulating the expression and activity of glycolytic enzymes. Therefore, blocking HIFl $\alpha$ expression by defensin may constitute a new and promising therapeutic option for the treatment of tumors (26).

In the investigation carried out by us, $A K T$ gene expression increased significantly. The findings achieved for the two cell lines HT-29 and A549 are significantly different under defensin action. At $15 \mu \mathrm{M}$ concentrations, cell apoptosis was 2-fold higher for the colorectal carcinoma line compared to alveolar carcinoma line. This explains $A K T$ gene expression increase in HT29 cells. $A K T$ is a serine/threonine kinase, which, activated by phosphorylation, leads to the decrease of the synthesis of certain proteins with an effector role, so that $A K T$ becomes an important molecular target in cancer therapy.

$N R F 2$ plays a protective role in the tumor cells as it is involved in resistance to cytostatic drugs and tumor progression. Also, increased NRF2 gene expression is associated with poor prognosis and multiple chemotherapy resistance.

Cathelicidin LL37 incubation of the HT-29 and A549 tumor cell lines allowed the determination of molecular markers used for toxicity monitoring and pro-apoptotic pathway assessment, by $C H O P$ gene expression and anti-apoptotic pathway expression, respectively, in the $B C L 2$ gene. $C H O P$ gene expression decrease and BCL2 increase in the HT29 line under the action of cathelicidin LL37 indicates tumor cell pro-apoptosis inhibition. Cell proliferation, tracked by $N R F 2$ gene expression, decreased significantly for both cell lines under the action of the LL37 peptide. The greatly inhibited cell growth and survival was highlighted by $A K T$ gene expression decrease.

IREI $\alpha$ gene expression that stimulate cancer progression, as well as $P I 3 K$ gene expression (stimulate the occurrence of membrane receptors on the surface of the tumor cells for various growth factors) only increased for cathelicidin LL37-incubated tumor cells indicating the presence of ER stress in tumor cells and also resistance to therapy.

Therefore, exposure of the two tumor cell lines (HT29, A549) to defensin or cathelicidin LL37 for $48 \mathrm{~h}$ was shown to be cytotoxic at low peptide concentrations $(4 \mu \mathrm{M})$.

In conclusion, the research conducted so far has demonstrated that defensin and cathelicidin LL37 have cytostatic effects on the HT29 and A549 tumor cell lines and allowed identification of molecular markers able to assess the growth, proliferation, survival, pro-apoptosis and anti-apoptosis pathways, as well as the methods of assessment and monitoring of tumor cell cytotoxicity by high-performance molecular biology techniques. In order to monitor the cytostatic effect of defensin on tumor cells, the following genes may be molecular targets for testing: i) $C H O P, B C L 2$ (by apoptosis activation); ii) $X B P$ (by oxidative stress augmentation in the cancer cell); iii) PERK, AKT (by protein synthesis inhibition) and iv) HIFla, $N R F 2$ (role in tumor proliferation and invasion). In order to monitor the therapeutic effect of cathelicidin LL37 on tumor cells, the following genes may be molecular targets for testing: i) $C H O P, B C L 2$ (by apoptosis activation); ii) $A K T$ (by protein synthesis inhibition) and iii) $N R F 2$ (role in tumor proliferation and invasion). The research conducted so far has proven that: i) defensin (strong) and cathelicidin LL37 (moderate) have cytostatic effects on the HT29 and A549 tumor cell lines and ii) allowed the identification of molecular markers able to assess the growth, proliferation, survival, pro-apoptosis and anti-apoptosis pathways; iii) methods of assessment and monitoring of tumor cell cytotoxicity by high-performance molecular biology techniques.

\section{Acknowledgements}

The authors thank Organizing Institution of University Doctoral Studies (IOSUD) of the University of Medicine and Pharmacy 'Grigore T. Popa' (Iasi, Romania), for the financial support to the PhD students: Teodor Ștefanache, Bogdan Mihail Diaconescu (2014-2018).

\section{Funding}

Partial funding by UMF 'Grigore T. Popa' (Iasi, Romania) was received.

\section{Availability of data and materials}

The datasets used and/or analyzed during the current study are available from the corresponding author on reasonable request.

\section{Authors' contributions}

$\mathrm{MB}$ and NF provided the study concepts and guaranteed the integrity of the entire study. TS, BMD, DJ were responsible for the study design, for literature research and statistical analysis. DJ and MLD were responsible for experimental studies and for data acquisition. MC, CB, ER interpreted the data and revised the work for important intellectual content. CR and $\mathrm{OB}$ analyzed the data of the study and prepared the discusions and conclusions of the study. CR, OB and DJ were responsible for manuscript preparation, editing and review. All authors read and approved the final manuscript.

\section{Ethics approval and consent to participate}

Not applicable.

\section{Patient consent for publication}

Not applicable.

\section{Competing interests}

The authors declare that the research was conducted in the absence of any commercial or financial relationships that could be construed as a potential conflict of interest. 


\section{References}

1. Hilchie AL, Vale R, Zemlak TS and Hoskin DW: Generation of a hematologic malignancy-selective membranolytic peptide from the antimicrobial core (RRWQWR) of bovine lactoferricin. Exp Mol Pathol 95: 192-198, 2013.

2. Sato $\mathrm{H}$ and Feix JB: Peptide-membrane interactions and mechanisms of membrane destruction by amphipathic $\alpha$-helical antimicrobial peptides. Biochim Biophys Acta 1758: 1245-1256, 2006.

3. Koczulla AR and Bals R: Antimicrobial peptides: Current status and therapeutic potential. Drugs 63: 389-406, 2003.

4. Homayouni-Tabrizi M, Asoodeh A and Soltani $M$ and Forghanifard MM: Antimicrobial peptide Brevinin-2R induces the secretion of a pro-inflamatory cytokine in HepG2 cells. J Bas Res Med Sci 2: 23-29, 2015.

5. Karadag R, Bayram N, Oguztuzun S, Bayramlar H, Bozer B, Simsek G and Rapuano CJ: An investigation of human beta-defensins and cathelicidin expression in patients with pterygium. Arq Bras Oftalmol 80: 277-280, 2017.

6. Zhuravel E, Shestakova T, Efanova O, Yusefovich Y, Lytvin D, Soldatkina $\mathrm{M}$ and Pogrebnoy P: Human beta-defensin-2 controls cell cycle in malignant epithelial cells: In vitro study. Exp Oncol 33: 114-120, 2011.

7. He M, Zhang H, Li Y, Wang G, Tang B, Zhao J, Huang Y and Zheng J: Cathelicidin-derived antimicrobial peptides inhibit zika virus through direct inactivation and interferon pathway. Front Immunol 9: 722, 2018.

8. Vermes I, Haanen C and Reutelingsperger C: Flow cytometry of apoptotic cell death. J Immunol Methods 243: 167-190, 2000.

9. Schleicher SM, Moretti L, Varki V and Lu B: Progress in the unraveling of the endoplasmic reticulum stress/autophagy pathway and cancer: Implications for future therapeutic approaches. Drug Resist Updat 13: 79-86, 2010.

10. Voiculescu VM, Caruntu C, Solomon I, Lupu M, Ilie MA, Boda D, Constantin C and Neagu M: Squamous cell carcinoma: Biomarkers and potential therapeutic targets. In: Human Skin Cancers-Pathways, Mechanisms, Targets and Treatments. Blumenberg M (ed). IntechOpen, London: pp135-159, 2018.

11. Neagu M, Caruntu C, Constantin C, Boda D, Zurac S, Spandidos DA and Tsatsakis AM: Chemically induced skin carcinogenesis: Updates in experimental models (Review). Oncol Rep 35: 2516-2528, 2016.

12. Boda D: Cellomics as integrative omics for cancer. Curr Proteomics 10: 237-245, 2013.

13. Neagu M, Constantin C, Tanase C and Boda D: Patented biomarker panels in early detection of cancer. Recent Pat Biomark 1: 10-24, 2011.

14. Kraskiewicz H and FitzGerald U: InterfERing with endoplasmic reticulum stress. Trends Pharmacol Sci 33: 53-63, 2012.

15. Zinszner H, Kuroda M, Wang X, Batchvarova N, Lightfoot RT, Remotti H, Stevens JL and Ron D: CHOP is implicated in programmed cell death in response to impaired function of the endoplasmic reticulum. Genes Dev 12: 982-995, 1998.
16. Park SH, Choi HJ, Yang H, Do KH, Kim J, Lee DW and Moon Y: Endoplasmic reticulum stress-activated C/EBP homologous protein enhances nuclear factor-kappaB signals via repression of peroxisome proliferator-activated receptor gamma. J Biol Chem 285: 35330-35339, 2010.

17. Lupu M, Caruntu A, Caruntu C, Papagheorghe LML, Ilie MA, Voiculescu V, Boda D, Constantin C, Tanase C, Sifaki M, Drakoulis N, Mamoulakis C, Tzanakakis G, Neagu M, Spandidos DA, Izotov B and Tsatsakis A: Neuroendocrine factors: The missing link in non melanoma skin cancer. Oncol Rep 38: 1327-13401, 2017.

18. Boda D, Docea AO, Calina D, Ilie MA, Caruntu C, Zurac S, Neagu M, Constantin C, Branisteanu DE, Voiculescu V, et al: Human papilloma virus: Apprehending the link with carcinogenesis and unveiling new research avenues (Review). Int J Oncol 52: 637-655, 2018

19. Solomon I, Voiculescu VM, Caruntu C, Lupu M, Popa A, Ilie MA, Albulescu R, Caruntu A, Tanase C, Constantin C, et al: Neuroendocrine factors and head and neck squamous cell carcinoma: An affair to remember. Dis Markers 2018: 9787831 , 2018.

20. Healy SJ, Gorman AM, Mousavi-Shafaei P, Gupta S and Samali A: Targeting the endoplasmic reticulum-stress response as an anticancer strategy. Eur J Pharmacol 625: 234-246, 2009.

21. Cioplea M, Caruntu C, Zurac S, Bastian A, Sticlaru L, Cioroianu A, Boda D, Jugulete G, Nichita L and Popp C: Dendritic cell distribution in mycosis fungoides vs. inflammatory dermatosis and other T-cell skin lymphoma. Oncol Lett 17: 4055-4059, 2019.

22. Del Poeta G, Venditti A, Del Principe MI, Maurillo L, Buccisano F, Tamburini A, Cox MC, Franchi A, Bruno A, Mazzone C, et al: Amount of spontaneous apoptosis detected by $\mathrm{Bax} / \mathrm{Bcl}-2$ ratio predicts outcome in acute myeloid leukemia (AML). Blood 101: 2125-2131, 2003.

23. Mitsuishi Y, Taguchi K, Kawatani Y, Shibata T, Nukiwa T, Aburatani H, Yamamoto $M$ and Motohashi H: Nrf2 redirects glucose and glutamine into anabolic pathways in metabolic reprogramming. Cancer Cell 22: 66-79, 2012.

24. Ren D, Villeneuve NF, Jiang T, Wu T, Lau A, Toppin HA and Zhang DD: Brusatol enhances the efficacy of chemotherapy by inhibiting the Nrf2-mediated defense mechanism. Proc Natl Acad Sci USA 108: 1433-1438, 2011.

25. Magesh S, Chen Y and Hu L: Small molecule modulators of Keap1-Nrf2-ARE pathway as potential preventive and therapeutic agents. Med Res Rev 32: 687-726, 2012.

26. Kong D, Park EJ, Stephen AG, Calvani M, Cardellina JH, Monks A, Fisher RJ, Shoemaker RH and Melillo G: Echinomycin, a small-molecule inhibitor of hypoxia-inducible factor-1 DNA-binding activity. Cancer Res 65: 9047-9055, 2005.

This work is licensed under a Creative Commons Attribution-NonCommercial-NoDerivatives 4.0 International (CC BY-NC-ND 4.0) License. 